\title{
Acute onset heart failure due to Marfan syndrome
}

\author{
Nicholas S. Hendren ${ }^{* 1}$, Shreya Rao ${ }^{1}$, Purav Mody ${ }^{2}$ \\ ${ }^{1}$ Department of Internal Medicine, The University of Texas Southwestern Medical Center, Dallas, Texas, USA \\ ${ }^{2}$ Division of Cardiology, Department of Internal Medicine, The University of Texas Southwestern Medical Center, Dallas, Texas, \\ USA
}

Received: September 7, 2016

DOI: $10.5430 /$ crim.v3n $4 p 78$
Accepted: October 7, $2016 \quad$ Online Published: October 9, 2016

URL: http://dx.doi.org/10.5430/crim.v3n4p78

\begin{abstract}
A 28-year-old visiting from Central America presented with twenty-four hours of lower extremity swelling, dyspnea and orthopnea. Clinically, she was diagnosed with acute heart failure requiring inotropes with a transthoracic echocardiogram revealing severe mitral regurgitation with a normal ejection fraction. Subsequent transesophageal echocardiogram confirmed severe mitral regurgitation with aortic root dilatation (Z-score: 3.9). She was also found to have arachnodactyly, scoliosis on X-ray and severe mitral valve prolapse. Given her clinical features she was assessed for Marfan syndrome with the modified Ghent nosology systemic score and met diagnostic criteria. A FBN1 genetic test confirmed the diagnosis of Marfan syndrome discovering a frameshift mutation resulting in an inappropriate stop codon and peptide truncation. For patients presenting with heart failure at an atypical age without typical risk factors, rare conditions such as Marfan syndrome should be considered. Marfan syndrome can accurately and quickly be screened for and diagnosed using the systemic score from the modified Ghent nosology.
\end{abstract}

Key Words: Marfan syndrome, Fibrillin-1, FBN1

\section{INTRODUCTION}

Heart failure is a common disease with an estimated 5.1 million people living with heart failure in the United States in $2013{ }^{[1]}$ The incidence of new heart failure increases with age as does the prevalence of traditional risk factors including hypertension, chronic kidney disease, diabetes, obesity and coronary artery disease. ${ }^{[2,3]}$ New onset heart failure in patients 18-30 years old is uncommon and was observed in the CARDIA cohort to have an overall incidence of $0.53 \%$ during 20 years of observation in 5,115 patients. ${ }^{[2]}$ While heart failure in patients younger than 30 years old can be due to typical causes, less common etiologies such as congenital heart disease, viral myocarditis, myocarditis, drug abuse and genetic conditions such as Marfan syndrome (MFS) should be considered.

\section{Clinichl case}

A 28-year-old female from Honduras with a medical history significant for atrial fibrillation, mitral valve regurgitation with prior mitral valve ring annuloplasty and hyperthyroidism was admitted with one day of progressive shortness of breath. One day after arrival to the United States she developed acute onset shortness of breath with associated palpitations, fatigue, activity intolerance, orthopnea and leg swelling over one day. For her atrial fibrillation she took amiodarone, nebivolol and rivaroxaban. Her medical history was notable for mitral valve regurgitation status post mitral valve repair two years prior to admission from a cardiac surgeon visiting in Honduras. She did not have a family history of MFS or other genetic conditions.

Her vital signs were: blood pressure $89 / 69 \mathrm{mmHg}$, pulse

*Correspondence: Nicholas S. Hendren, MD; Email: nicholas.hendren@phhs.org; Address: UT Southwestern Department of Internal Medicine, Division of Internal Medicine, 5323 Harry Hines Blvd, Dallas, TX 75235, USA. 
$85-95$, weight $52.1 \mathrm{~kg}$, height 167.6 inches and body mass index of $18.6 \mathrm{~kg} / \mathrm{m}^{2}$. Generally she appeared comfortable without acute distress. Her eye exam was notable for enophthalmos with normal pupils, acuity and visual fields. Her cardiac exam had an irregular heart rate with a loud P2 and 2/6 holosystolic murmur radiating to the axilla with a displaced point of maximal impact. Her jugular venous pulse was elevated to the angle of the mandible at about 45 degrees. Her pulmonary exam, abdominal and neurological exams were unremarkable. On musculoskeletal exam she had retrognathia and malar hypoplasia, pectus carinatum, scoliosis, arachnodactyly with a positive thumb sign and pes planus. Her vascular exam was notable for cool lower extremities with bilateral trace edema consistent with acute heart failure and volume overload.

Admission labs demonstrated hyponatremia, hypokalemia and normocytic anemia with normal renal function (see Table 1). Serial troponins were negative with an elevated NTproBNP of 4,666 pg/ml. A chest X-ray demonstrated pulmonary edema, scoliosis and cardiomegaly (see Figure 1) and an ECG demonstrated atrial fibrillation with right axis deviation. A transthoracic echocardiogram found a dilated left ventricle (ejection fraction 56\%, end diastolic volume $203 \mathrm{ml}$, left ventricular length diastole $8.7 \mathrm{~cm}$ ), dilated right ventricle, dilated left atrium, posterior mitral valve annuloplasty ring with significant valve thickening and mitral valve posterior leaflet prolapse with resultant severe mitral regurgitation (see Figure 2). A subsequent transesophageal echocardiogram confirmed the transthoracic findings and demonstrated previous mitral valve repair, an enlarged aortic root $(3.9 \mathrm{~cm})$ and prominent prolapse of the posterior mitral valve leaflet with a perforation of the posterior leaflet contributing to severe mitral valve regurgitation. A coronary angiogram did not have angiographic evidence of obstructive coronary artery disease. On right heart catheterization she had an elevated capillary wedge pressure $(31 \mathrm{mmHg})$, a large V-wave and low cardiac index $(1.72 \mathrm{~L} / \mathrm{min})$ consistent with severe mitral valve regurgitation.

Table 1. Admission labs

\begin{tabular}{lll}
\hline Lab & Result & Normal \\
\hline Sodium & 133 & $135-145 \mathrm{mmol} / \mathrm{liter}$ \\
Potassium & 3.5 & $3.6-5.0 \mathrm{mmol} / \mathrm{liter}$ \\
Calcium & 8.0 & $8.4-10.2 \mathrm{mg} / \mathrm{dl}$ \\
Anion Gap & 14 & $12-16$ \\
Blood Urea & 21 & $6-23 \mathrm{mg} / \mathrm{dl}$ \\
Creatinine & 0.74 & $0.67-1.17 \mathrm{mg} / \mathrm{dl}$ \\
NT-BNP & 4,666 & $<300 \mathrm{pg} / \mathrm{ml}$ \\
Troponin T & $<0.01$ & $<0.01$ \\
Thyroid Stimulating Hormone & 17.11 & $0.40-4.50 \mathrm{mcIU} / \mathrm{ml}$ \\
Free T4 & 1.0 & $0.8-1.8 \mathrm{ng} / \mathrm{dl}$ \\
\hline
\end{tabular}

Published by Sciedu Press

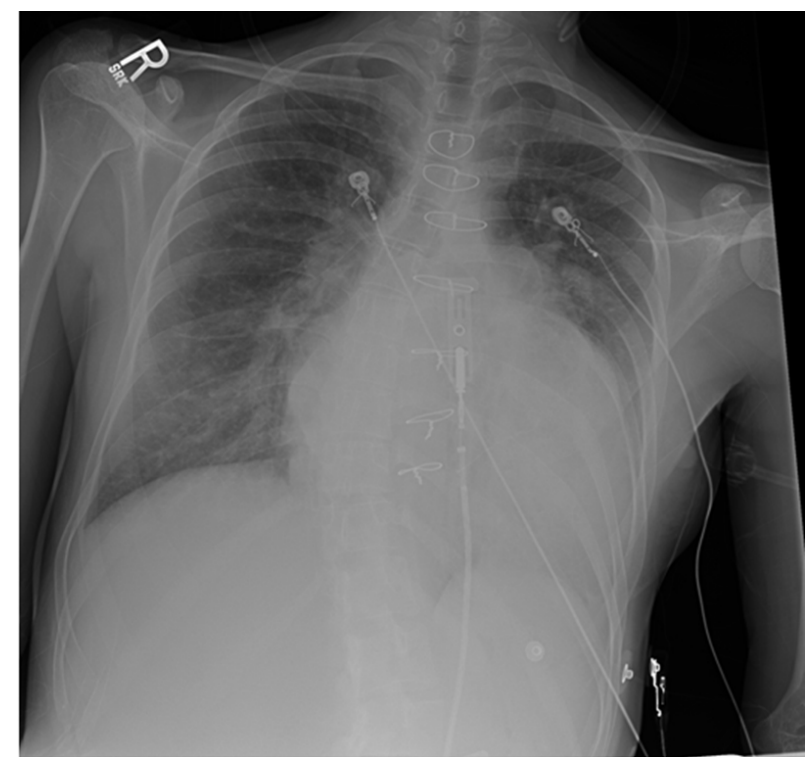

Figure 1. Admission Chest X-Ray: Notable for significant cardiomegaly and interstitial opacities consistent with pulmonary edema. Sternal wires, scoliosis and possible small left pleural effusion are also noted

Due to her enlarged aortic root, prominent mitral leaflet prolapse, scoliosis and arachnodactyly, de novo MFS was suspected. She was evaluated with the modified Ghent nosology and met the diagnostic criteria. Her systemic score was determined to be 9 (positive score $>7$, see Tables $2 \& 3$ ). Her enlarged aortic root had a calculated z-score of 3.9 (positive z-score > 2) using the Marfan.org diagnostic software. Subsequent FBN1 gene sequencing discovered a frameshift mutation resulting in premature peptide truncation due to an early stop codon that was consistent with MFS.

Table 2. Modified ghent nosology systemic score criteria and scoring for patient (Loeys BL, et al.)

\begin{tabular}{lll}
\hline \multicolumn{1}{c}{ Systemic Score } & & \\
\hline Findings & Points & $\begin{array}{l}\text { Patient } \\
\text { Points }\end{array}$ \\
\hline Wrist and thumb sign (wrist OR thumb sign) & $3(1)$ & 3 \\
Pectus carinatum (chest asymmetry) & $2(1)$ & 2 \\
Hindfoot valgus (flat fleet) & $2(1)$ & 1 \\
Any spontaneous pneumothorax & 2 & 0 \\
Lumbosacral dural ectasia & 2 & Not \\
& & assessed \\
Protrusio acetabuli & 2 & Not \\
Scoliosis (Cobb angle $\left.>20^{\circ}\right)$ or Thoracolumbar Kyphosis & 1 & 1 \\
Full elbow extension $\left(<170^{\circ}\right)$ & 1 & 0 \\
3 of 5 facial features & 1 & 1 \\
Skin striae & 1 & 0 \\
Severe myopia & 1 & 0 \\
Mitral valve prolapse & 1 & 1 \\
Upper/Lower ratio and arm span/height ratio & 1 & Not \\
Total score & $\mathbf{2 0}$ & $\mathbf{9}$ \\
\hline Note Maximum total: 20 points; score $>7$ indicates systemic
\end{tabular}



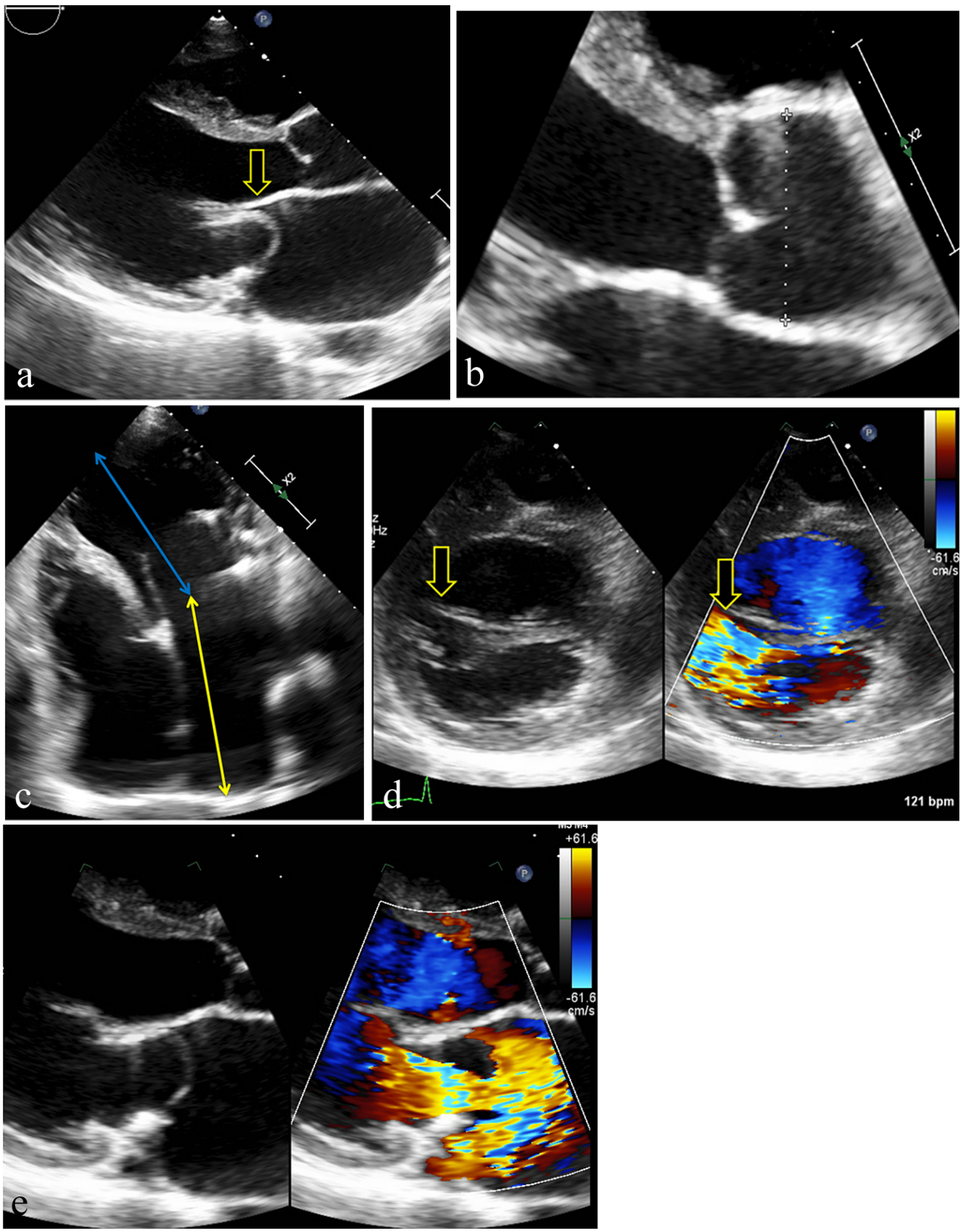

Figure 2. Transthoracic Echocardiogram. a. Markedly dilated left atrium with mitral valve posterior leaflet prolapse (arrow) on apical view; b. $3.9 \mathrm{~cm}$ dilation of aortic root (Marfan.org z-score = 3.8); c. Four-chamber view with dilated left ventricle (blue line, left ventricular internal diameter end diastole $7.2 \mathrm{~cm}$ ), dilated left atrium (yellow line, left atrium dimension $6.5 \mathrm{~cm}$ ), mildly dilated right ventricle; $d$. Severe mitral valve regurgitation noted on a parasternal short axis view (arrows); E. Parasternal long view demonstrating severe mitral valve regurgitation

On day three, she went into atrial fibrillation with rapid ventricular rates. Her heart rate was adequately controlled with a bolus of $150 \mathrm{mg}$ of amiodarone and 15 total $\mathrm{mg}$ of in- travenous metoprolol; however, this resulted in cardiogenic shock requiring the initiation of milrinone. She continued to frequently revert into and out of normal sinus rhythm 
over the next several days despite adequate rate control. She was gradually stabilized with aggressive diuresis, continuation of amiodarone, initiation of digoxin and initiation of hydralazine. Milrinone was weaned off within 72 hours and on day seventeen she underwent mechanical mitral valve replacement without intra-operative complications. Intraoperatively the surgeon discovered a prior posterior annulus repair with approximately $75 \%$ dehiscence resulting in a large perforation in the mitral valve. The native valve also had features of rheumatic disease including leaflet thickening, papillary cord fusion, papillary cord shortening and papillary muscle fibrosis. Valve pathology demonstrated calcifications, fibrosis and chronic inflammation with rare multinuclear giant cells consistent with rheumatic valve disease. She was discharged from the hospital on post-operative day twelve and seen in clinic one month later with a repeat echocardiogram demonstrating preserved left ventricular function without paravalvular leak.

Table 3. Modified ghent nosology (Loeys BL, et al.)

\begin{tabular}{|c|}
\hline Modified Ghent Nosology \\
\hline In the absence of family history \\
\hline Ectopia lentis and documented FBN1 mutation with known Aortic Root Dilatation $=$ MFS \\
\hline Aortic Root Dilatation Z score $\geq 2$ and Documented FBN1 mutation $=$ MFS \\
\hline Aortic Root Dilatation Z score $\geq 2$ and Ectopia Lentis $=$ MFS \\
\hline Aortic Root Dilatation Z score $\geq 2$ and Systemic Score $\geq 7$ pts $=$ MFS \\
\hline In the presence of family history \\
\hline A systemic score $\geq 7$ points and family history of Marfan syndrome $=$ MFS \\
\hline Ectopia lentis and family history of Marfan syndrome = MFS \\
\hline Aortic Root Dilatation ( $Z$ score $\geq 2$ older than 20 years old) and family history of Marfan syndrome $=$ MFS \\
\hline $\begin{array}{ll} & \text { Patient Scoring } \\
\end{array}$ \\
\hline Systemic score \\
\hline 9 (score $>7$ indicates systemic involvement) \\
\hline Family history of Marfan syndrome \\
\hline Negative \\
\hline Aortic dilation Z-score \\
\hline 3.8 (positive $\mathrm{z}$-score $>2$ ) \\
\hline FBN1 genetic test \\
\hline $\begin{array}{l}\text { Positive for mutation in FBN1 gene, exon } 36 \text {, nucleotide } 4,562 \text { there was a deletion resulting in a frame shift that resulted in a } \\
\text { premature stop codon } 59 \text { positions downstream }\end{array}$ \\
\hline
\end{tabular}

Note. Family history of Marfan syndrome should be defined using the Modified Ghent nosology.

\section{Discussion}

Originally described in 1896, MFS results from various mutations within the fibrillin-1 (FBN1) gene and is inherited in an autosomal dominant fashion with roughly $25 \%$ de novo mutations and an estimated prevalence of $15-172$ per $1,000,000$ people. ${ }^{[5,6]}$ The FBN1 gene produces fibrillin an integral protein for formation of the extracellular matrix in connective tissue. MFS occurs in both sexes and all races without known differences in incidence. ${ }^{[7]}$ The 2010 modified Ghent nosology sought to simplify, improve diagnostic accuracy and allow for an earlier diagnosis of MFS. ${ }^{6]}$ Our patient met the modified Ghent criteria (see Tables $2 \& 3$ ) with a positive systemic score, aortic root dilation z-score and FBN1 mutation. Although our patient met diagnostic criteria prior to genetic testing, given the presumed de novo mutation we elected to obtain genetic testing for family genetic counseling.

MFS is a systemic disease affecting multiple organ sys-

Published by Sciedu Press tems including the cardiovascular, pulmonary, connective tissue, skin, ocular and skeletal systems. ${ }^{[7]}$ The modified Ghent nosology continues to serve as the gold standard for the diagnosis of MFS as mutations in the FBN1 gene are necessary, but not sufficient to diagnose MFS. FBN1 mutations in patients without clinical symptoms of MFS have underdetermined clinical significance. ${ }^{[6]}$ Researchers have created a universal FBN1 mutation database (http: //www. umd.be/FBN1/) that contains over three thousand mutations in an effort to improve our ability to predict which mutations may produce systemic disease. ${ }^{[8]}$

Recognizing MFS is important to assess for cardiovascular complications, which historically were the leading cause of death for patients with MFS. Most individuals with MFS have cardiac abnormalities including a dilated aorta $(60 \%$ $80 \%)$, dilated descending aorta $(80 \%-100 \%)$, mitral regurgitation and/or mitral valve prolapse $(50 \%-80 \%) .{ }^{[9,10]}$ Dilated 
pulmonary arteries are common (76\%), but are rarely clinically significant. ${ }^{[9]}$ Less common findings include atrial septal defects (4\%), tricuspid valve prolapse (4\%), arrhythmias and left ventricular dysfunction. ${ }^{[9]}$ For patients with MFS, prior to open heart surgery and prophylactic aortic arch replacement, the average life expectancy was 32-yearold and an estimated $90 \%$ of untimely deaths were attributed to cardiovascular sequelae. ${ }^{[11]}$ Recommendations for cardiac monitoring include an echocardiogram at diagnosis for all patients followed by another echocardiogram six months after initial diagnosis. ${ }^{[11]}$ If there is no aortic root dilation, yearly echocardiograms are reasonable. If a patient is found to have aortic root dilation more frequent screening is recommended; however, no formal guidelines exist. ${ }^{[11]}$ Current guidelines recommend if the aortic root is $>5.0 \mathrm{~cm}$ or dilation progresses at $>0.5 \mathrm{~cm}$ yearly ascending aortic arch replacement should be considered. ${ }^{[4,12]}$ Recent studies have documented a significantly increased life expectancy that approaches the general population with appropriate medical therapy and aortic root replacement. ${ }^{[11]}$

Despite insight into the genetics of the disease, pharmacologic treatments have not demonstrated consistent efficacy in reducing the rate of aortic root dilation in MFS. ${ }^{[13]}$ Betablockers are a cornerstone of therapy for Marfan syndrome and is the primary pharmacologic treatment recommended in current guidelines. ${ }^{[4]}$ The recommendation is largely based upon a single open-label placebo-controlled study of $70 \mathrm{pa}-$

\section{REFERENCES}

[1] Go AS, Mozaffarian D, Roger VL, et al. Heart disease and stroke statistics-2014 update: a report from the American Heart Association. Circulation. 2014. 129(3): e28-e292. PMid:24352519 http: //dx.doi.org/10.1161/01.cir.0000441139.02102.80

[2] Bibbinsdomingo K, Pletcher MJ, Lin F, et al. Racial differences in incident heart failure among young adults. N Engl J Med. 2009; 360(12): 1179-90. PMid:19297571 http://dx.doi.org/10.10 56/NEJMoa0807265

[3] Roger VL. Epidemiology of heart failure. Circ Res. 2013; 113(6): 646-59. PMid:23989710 http://dx.doi.org/10.1161/CIRCR ESAHA.113. 300268

[4] Loeys BL, Dietz HC, Braverman AC, et al. The revised Ghent nosology for the Marfan syndrome. J Med Genet. 2010; 47(7): 476-85. PMid:20591885 http://dx.doi.org/10.1136/jmg.2 009.072785

[5] Ramachandra CJA, Mehta A, Guo KWQ, et al. Molecular pathogenesis of Marfan syndrome. Int J Cardiol. 2015; 187: 58591. PMid:25863307 http://dx.doi.org/10.1016/j.ijcard. 2015.03 .423

[6] Von KY, De BJ, Schüler H, et al. Perspectives on the revised Ghent criteria for the diagnosis of Marfan syndrome. Appl Clin Genet. 2015; tients taking propranolol, which did not find a statistically significant difference in a clinical end-point composite of death, congestive heart failure, aortic regurgitation, aortic dissection or cardiovascular surgery (5vs. 9). ${ }^{[14]}$ The study did find a significant difference in the rate of aortic dilation with propranolol as compared to placebo over an approximate 10-year follow-up; however, it remains unclear if this reduction is clinically meaningful. ${ }^{[14]}$ To date we are not aware of any randomized double-blinded studies demonstrating the efficacy of beta-blockers in reducing the rate of aortic dilation or reducing clinical end-points in patients with MFS. Beta-blockers impact on long-term survival and the rate of complications remains unclear. ${ }^{[11]}$ Regardless, beta-blocker therapy is recommended in all patients with MFS and our patient was continued on beta-blockers at discharge. ${ }^{[11]}$

Our case describes acute heart failure and cardiogenic shock due to an uncommon presentation of cardiac complications from MFS requiring mechanical mitral valve replacement. Our patient had a de novo mutation of the FBN1 gene with several classic findings of MFS including scoliosis, severe mitral valve prolapse, dilated ascending aorta and pectus carinatum meeting diagnostic criteria of the modified Ghent nosology. After surgical treatment for her mitral valve regurgitation our patient's cardiac function improved with optimal medical therapy and was maintained at one month follow-up.

\section{CONFlicts OF InTEREST Disclosure}

The authors have declared no conflicts of interest.

\section{8: 137-55.}

[7] Collod-Beroud G, Boileau C. Marfan syndrome in the third Millennium. Eur J Hum Genet. 2002; 10(11): 673-81. PMid:12404097 http://dx.doi.org/10.1038/sj.ejhg. 5200876

[8] Collod-Béroud G, Bourdelles SL, Ades L, et al. Update of the UMD-FBN1 mutation database and creation of an FBN1 polymorphism database. Hum Mutat. 2003; 22(3): 199-208. PMid:12938084 http://dx.doi.org/10.1002/humu.10249

[9] Stuart AG, Williams A. Marfan's syndrome and the heart. Arch Dis Child. 2007; 92(4): 351-6. PMid:17376944 http://dx.doi.org /10.1136/adc. 2006.097469

[10] Cañadas V, Vilacosta I, Bruna I, et al. Marfan syndrome. Part 1: pathophysiology and diagnosis. Nat Rev Cardiol. 2010; 7(5): 256-65.

[11] Cañadas V, Vilacosta I, Bruna I, et al. Marfan syndrome. Part 2: treatment and management of patients. Nat Rev Cardiol. 2010; 7(5): 266-76.

[12] Hiratzka LF, Bakris GL, Beckman JA, et al. 2010 ACCF/AHA/AATS/ACR/ASA/SCA/SCAI/SIR/STS/SVM Guidelines for the diagnosis and management of patients with thoracic aortic disease: Executive summary: A report of the American College of Cardiology Foundation/American Heart Association Task Force on Practice Guidelines, American Association for Thoracic Surgery, 
American College of Radiology, American Stroke Association, Society of Cardiovascular Anesthesiologists, Society for Cardiovascular Angiography and Interventions, Society of Interventional Radiology, Society of Thoracic Surgeons, and Society for Vascular Medicine. Anesth Analg. 2010; 111(2): 279-315. PMid:20664093 http://dx.doi.org/10.1213/ANE.0b013e3181dd869b

[13] Lacro RV, Dietz HC, Sleeper LA, et al. Atenolol versus losartan in children and young adults with Marfan's syndrome. N Engl J Med. 2014; 371(22): 2061-71.

[14] Shores J, Berger KR, Murphy EA, et al. Progression of aortic dilatation and the benefit of long-term beta-adrenergic blockade in Marfan's syndrome. N Engl J Med. 1994; 330(19): 133541. PMid:25405392 http://dx.doi.org/10.1056/NEJMoa140 4731 